\section{Congenital hypoparathyroidism misdiagnosed as infantile seizure}

Umar Isa Umar, Ibrahim Aliyu, Mahmud Gambo Jahun, Umar Abba Sabo, Garba Dayyabu Gwarzo

Department of Paediatrics, Aminu Kano Teaching Hospital, Bayero University, Kano, Nigeria

\begin{abstract}
The occurrence of seizure in children is a common neurologic dysfunction and finding the underlying aetiology is critically important as it determines the prognosis and outcome of the seizure and also guides therapeutic strategies. Parathyroid hormone (PTH) plays key role in the complex controlling mechanisms regulating calcium and phosphate balance. An insufficient circulating PTH level is a common cause of hypocalcaemia. A 3-months-old infant was referred to our endocrine unit with recurrent seizures, body stiffness, noisy breathing and bilateral cataract. He was previously been diagnosed as epilepsy in a syndromic child. Biochemical investigation revealed hypoparathyroidism, brain MRI was suggestive of decrease myelination for age, EEG revealed normal study, and a diagnosis of congenital hypoparathyroidism was confirmed. After calcium and vitamin D replacement, the infant improved and was seizure free off antiepileptic therapy. This case therefore explores an unusual case of seizure disorder. It further highlights the fact that not all epilepsies are cryptogenic or genetic epilepsy, therefore treatable acute symptomatic etiologies should be adequately searched.
\end{abstract}

\section{Introduction}

Seizures in neonates are relatively common and often encountered by general practitioners. Their presence may be the first sign of neurologic dysfunction, and they are powerful predictors of long-term cognitive and developmental impairment. ${ }^{1}$ Patients are often labeled as cryptogenic or idiopathic epilepsy, and in some cases, appropriate investigations to assess for provoking factors and/or treatable causes are overlooked.

Hypocalcaemia is a common cause of seizures in children and its serum concentration is maintained within a narrow physiological range by complex controlling mechanisms. The most prominent mecha- nisms are; Parathyroid Hormone (PTH), active vitamin D [1,25-(OH $)_{2}$ D], and Calcium Sensor Receptors (CaSRs) acting in renal, intestinal, parathyroid, and bone tissues to maintain the calcium homeostasis. Failure of any of these homeostatic mechanisms or inadequate compensation hypocalcaemia occurs. ${ }^{2}$ Hypoparathyroidism can be acquired, inherited, or idiopathic, and is caused by inability to synthesize or secrete PTH, abnormal parathyroid gland development, destruction of parathyroid tissue or resistance of circulating PTH (pseudohypoparathyroidism). ${ }^{2}$

Decreases in serum calcium are recognized by CaSRs in the parathyroid glands, stimulating PTH production and secretion. The PTH acts to promote calcium reabsorption in the kidney and stimulates the release of calcium from bone, and thus, restores serum calcium levels to normal. Also elevation in serum PTH increases renal 1,25$(\mathrm{OH})_{2}$ Vit D production which stimulates both calcium and phosphate absorption across the small intestine. Achievement of eucalcaemia then leads to a downward readjustment in the PTH secretory rate. ${ }^{3}$ Signs and symptoms of hypoparathyroidism are related to hypocalcaemia. Seizures are common manifestation of hypocalcaemia in children, which may mimic seizure disorder. ${ }^{3}$

This case report highlights such a scenario when an infant with hypocalcaemiaassociated seizures due to underlying idiopathic hypoparathyroidism was treated for idiopathic epilepsy.

\section{Case Report}

A 3-months-old infant was referred to our endocrine unit with recurrent seizures, body stiffness and noisy breathing. He was born at term (39 weeks gestation) to third degree consanguineous parents. The delivery was normal with no adverse perinatal events. He had multiple episodes of abnormal movements in the form of sudden tonic stiffening of all four limbs from day 3 of life, with irritability. At the age of 2 weeks he developed low grade fever with increased seizures. He was managed for suspected meningitis with antibiotics and anticonvulsants at the referring hospital, even though the meningitis was treated without confirmation. The fever disappeared but seizures continued despite change of anticonvulsant from phenobarbitone to carbamazepine. He was then diagnosed with infantile seizure because of the persistent seizures. However, parents absconded, stopped all medications and resorted to prayer therapy because they
Correspondence: Umar Isa Umar, Department of Paediatrics, Bayero University, P.M.B. 3011, Kano, Nigeria

Tel.: 07036068723.

E-mail: umarpaed@gmail.com

Key words: Congenital hypothyroidism; seizure disorder; epilepsy, hypoparathyroidism.

Availability of data and materials: All data underlying the findings are fully available.

Ethics approval and consent to participate: No ethical committee approval was required for this case report by the Department, because this article does not contain any studies with human participants or animals. Informed consent was obtained from the patient included in this study.

Consent for publication: The patient's guardians gave their consent to use the personal data for the publication of this case report and any accompanying images.

Received for publication: 17 June 2019

Revision received: 26 November 2019.

Accepted for publication: 26 November 2019.

This work is licensed under a Creative Commons Attribution NonCommercial 4.0 License (CC BY-NC 4.0).

(C) Copyright: the Author(s), 2020

Licensee PAGEPress, Italy

Pyramid Journal of Medicine 2020; 3:55

doi:10.4081/pjm.2020.55

believed that the child was possessed by evil spirits. By 3 months of life the child had deteriorated and was taken back to the referring hospital. Unfortunately, he had developed stiffness of all four limbs and was noted to have bilateral cataract with associated noisy breathing. He was subsequently referred to our unit for second opinion. On examination, his general vitals were stable, there was no overt dysmorphism, and he had intermittent stridor. He was alert and awake, with roving eye movements, and bilateral leucocoria, there was no facial asymmetry. He had abnormal posture. There was retrocolis, the upper limbs were fisted and flexed while both lower limbs extended with hypertonicity of all four limbs. He had brisk reflexes and bilateral ankle clonus. Other system - not contributory. The biochemical investigations, revealed an initial serum calcium $6.9 \mathrm{mg} / \mathrm{dL}(8.8$ 10.8) and phosphorus $10.9 \mathrm{mg} / \mathrm{dL}$ (4-7), repeated serum calcium $6.4 \mathrm{mg} / \mathrm{dL}$, phosphorus $10.6 \mathrm{mg} / \mathrm{dL}$. Alkaline phosphatase $261 \mathrm{U} / \mathrm{L}(<449)$, Magnesium $1.9 \mathrm{mg} / \mathrm{dL}$ (1.7-2.3), albumin $4.3 \mathrm{~g} / \mathrm{dl}$ (3.5-5.2), 25- 
hydroxy vitamin-D $95.28 \mathrm{nmol} / \mathrm{L}$ (75-185), TSH $-6.0 \mu \mathrm{U} / \mathrm{mL}(0.7-6.4)$, free T4 1.50 $\mathrm{ng} / \mathrm{dL}$ (0.8-2.0), random blood sugar (RBS) $90 \mathrm{mg} / \mathrm{dL}$. Urea, electrolytes, creatinine $(\mathrm{U} / \mathrm{E} / \mathrm{Cr}$ ) and Complete Blood Count (CBC) were essentially normal. Serum parathyroid hormone (PTH) was $10.6 \mathrm{pg} / \mathrm{mL}$ (14-72 $\mathrm{pg} / \mathrm{mL}$ ), confirming a diagnosis of hypoparathyroidism. Genetic panel for exome sequencing for pathogenic gene variations was sought, and the result showed no pathogenic or possibility of pathogenic variations to be the cause of the clinical symptoms detected. Brain-magnetic resonance imaging (MRI) revealed generalized hypomyelination in both cerebral hemispheres (Figure 1), abdominal scan and Brain-electroencephalogram (Figures 2 and 3 ) revealed normal studies.

\section{Discussion}

A neonate presenting with definite new onset seizures, investigations for any provocative factors that may cause the seizures are recommended. There are many possible reasons for neonatal seizures, and careful and thorough history can give a clue to the most likely cause in most situations. Neonatal seizures can be from HypoxicIschemic Encephalopathy (HIE), ${ }^{1,4}$ intracranial haemorrhage, ${ }^{5}$ metabolic disorders like hypoglycemia, hypocalcaemia, hypomagnesaemia and others such as inborn errors of metabolism. ${ }^{5}$ Other causes are genetic disorders due to genetic mutations, ${ }^{6}$ intracranial infections, malformation syndromes and benign neonatal seizure syndromes. ${ }^{5}$

Our patient started having seizures from third day of life with no associated history of fever at the onset to suggest possibility of

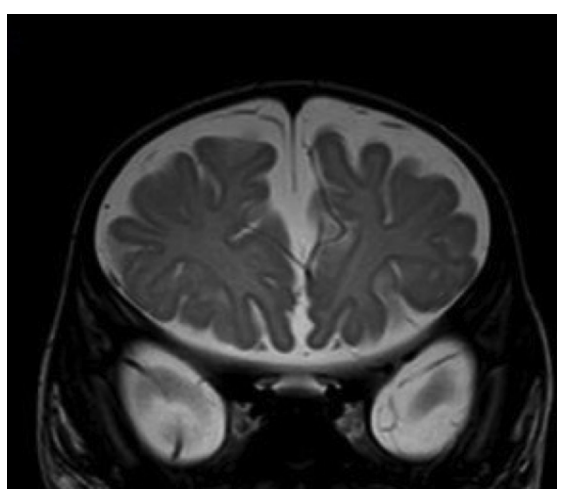

Figure 1. MRI revealing generalized hypomyelination in both cerebral hemispheres. infections, or adverse perinatal events to suggest possible HIE or intracranial haemorrhage. Furthermore, there was no family history of seizures to suggest benign familial neonatal seizures. However, there may be possibility of genetic disorders because of history of consanguinity in the family. In addition, metabolic disorders could also be likely, because these are common causes of neonatal seizures in the absence of fever or adverse perinatal events, and they tend to commonly cause symptoms from the third day of life. Therefore, when this patient presented at the age of two weeks with history of increased seizures, meningitis should not have been the most likely cause of the seizures. Other common possibilities should have been considered like metabolic disorders. Therefore we thought hypocal- caemia secondary to hypoparathyroidism is the cause of seizures in this patient because of the repeated low serum calcium and low PTH. According to International League Against Epilepsy (ILAE), to attribute a seizure to an electrolyte abnormality, the biochemical derangement should be detected within 24 hours of the seizure. ${ }^{7,8}$ Hypocalcemic-related seizures depend on the rate of decrease in serum calcium and degree of hypocalcemia. ${ }^{8}$ The resultant hypocalcaemia results in increased neuronal excitability due to reduced extracellular concentration of calcium rather than depleted intracellular levels and both generalised tonic-clonic or focal seizures can occur with hypocalcemia. ${ }^{9,10}$ The finding in this report is similar to what was reported by Mine et al in Turkey who reported an infant with

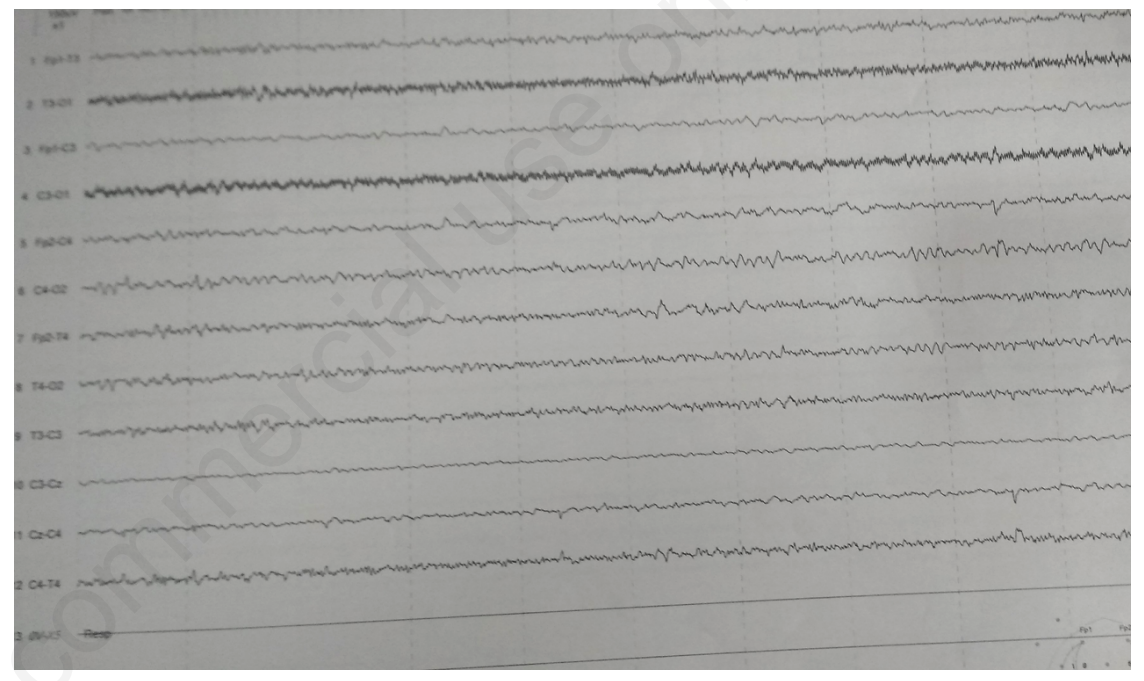

Figure 2. Brain-electroencephalogram revealing normal studies.

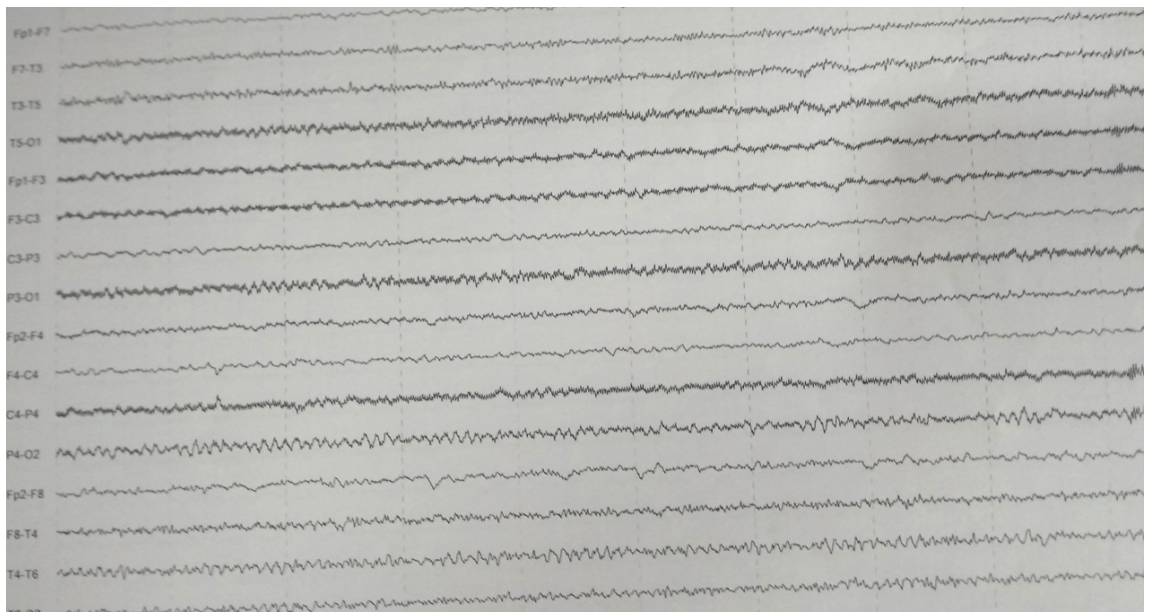

Figure 3. Brain-electroencephalogram revealing normal studies. 
similar presentation due to hypoparathyroidism. ${ }^{11}$ Kunstadter et al. ${ }^{12}$ also reported two neonates with idiopathic hypoparathyroidism with repeated seizures. Furthermore, in South Africa, Seedat et al. reported a case of acute symptomatic seizures in an adult, which are caused by idiopathic hypoparathyroidism other than epilepsy. ${ }^{13}$

Hypoparathyroidism can be acquired, inherited, or idiopathic, and is caused by inability to synthesize or secrete PTH, abnormal parathyroid gland development, destruction of parathyroid tissue, peripheral resistance to $\mathrm{PTH}$, or due to genetic disorder causing activating mutations in the CaSR. ${ }^{14}$

Other possible diagnoses considered in this child were early infantile onset heredodegenerative disease, mitochondrial cytopathy, hypomyelinating leukodystrophy, peroxisomal disorder, Kearns-Sayre syndrome, neurotransmitter defect or PelizaeusMerzbacher. But the genetic study did not show any pathogenic or likely pathogenic variations to be causative of the clinical symptoms detected. However, genetic tests may not always give a definitive answer, ${ }^{15}$ in some cases, testing may not identify a genetic variant even though one exists. This may be due to limitations in current medical knowledge or testing technology. Accordingly, variants in regions of insufficient coverage may not be identified and/or interpreted. Therefore, it is possible that pathogenic variants are present in one or more of the genes analysed, but have not been detected. The patient was therefore diagnosed as idiopathic hypoparathyroidism with neurologic sequalae (spastic quadriplegia, visual and hearing impairment).

Child was managed with oral calcium and calcitriol (vitamin $D_{3}$ ) for the hypoparathyroidism. It is recommended to use oral calcium and vitamin D supplementation as therapy for hypoparathyroidism, but serum calcium should be maintained in the lower range of normal to avoid hypercalciuria and resultant nephrolithiasis. ${ }^{16}$ Anticonvulsants are used for seizures control in hypoparathyroidism, commonly used agents are phenytoin, valproate, carbamazepine, and levetiracetam. ${ }^{17}$ In this study, anticonvulsant (valproate) was con- tinued for 2 years before it was weaned completely, and the child has enjoyed seizure freedom for 4 years now. Additional supportive management was oral baclofen for spasticity and physiotherapy for delayed motor development. The child had cataract extraction at the age of 18 months and regained full vision. His serum calcium was in the range of 1.7-2.1 $\mathrm{mmol} / \mathrm{L}$ in the last four clinic visits. So far, he is seizure free, no stridor and has regained full vision and hearing, but is yet to achieve neck control or sit unsupported.

\section{Conclusions}

This case highlights the importance of searching for etiology of epilepsy in all cases rather than classifying most epilepsies cryptogenic or genetic as there are many acute symptomatic and some remote symptomatic epilepsies out there that are amenable to treatment like our index case!

\section{References}

1. Volpe JJ. Hypoxic-Ischemic Encephalopathy: Biochemical and Physiological Aspects. Neurology of the Newborn. 4th ed. Philadelphia: WB Saunders; 2000: pp. 217-276.

2. Maeda SS, Fortes EM, Oliveira UM, Borba VC, Lazaretti-Castro M. Hypoparathyroidism and pseudohypoparathyroidism. Arq Bras Endocrinol Metabol 2006;50:664-73.

3. Brook CGD, Brown RS. Handbook of Clinical Pediatric Endocrinology, 1st edition. Blackwell Publishing; 2008: pp. 33-58.

4. Silverstein FS, Jensen FE. Neonatal seizures. Ann Neurol 2007;62:112-20.

5. Sheth RD, Hobbs GR, Mullett $M$. Neonatal seizures: incidence, onset, and etiology by gestational age. J Perinatol 1999;19:40-3.

6. Hwang SK, Kwon S. Early-onset epileptic encephalopathies and the diagnostic approach to underlying causes. Korean J Pediatr 2015;58:407-14.

7. Beghi E, Carpio A, Forsgren L, et al. Recommendation for a definition of acute symptomatic seizure. Epilepsia 2010;51:671-5.

8. Nardone R, Brigo F, Trinka E. Acute symptomatic seizures caused by electrolyte disturbances. J Clin Neurol 2016;12:21-33.

9. Han P, Trinidad BJ, Shi J. Hypocalcemia-induced seizure: demystifying the calcium paradox. ASN Neuro 2015;7:19-22.

10. Maeda SS, Moreira CA, Borba VZC, et al. Diagnosis and treatment of hypoparathyroidism: a position statement from the Brazilian Society of Endocrinology and Metabolism. Arch Endocrinol Metab 2018;62:106-24.

11. Mine C, Osman K, Selim K, et al. An Infant with Neonatal Hypoparathyroidism: Case Report. Turkish J Endocrinol Metab 1999;3: 149-52.

12. Kunstadter RH, Oh W, Tanman F, et al. Idiopathic Hypoparathyroidism in the NewbornReport of Two Cases Born of Diabetic Mothers. Am J Dis Child 1963;105:499-506.

13. Seedat F, Daya R, Bhana SA. Hypoparathyroidism Causing Seizures: When Epilepsy Does Not Fit. Case Rep Med 2018;2018:5948254.

14. Al-Azem H, Khan AA. Hypoparathyroidism. Best Pract Res Clin Endocrinol Metab 2012;26:51722.

15. Richards S, Aziz N, Bale S, et al. Standards and guidelines for the interpretation of sequence variants: a joint consensus recommendation of the American College of Medical Genetics and Genomics and the Association for Molecular Pathology. Genet Med 2015;17:405-24.

16. Goswami R, Sharma V, Sreenivas N, et al. Prevalence and progression of basal ganglia calcification and its pathogenic mechanism in patients with idiopathic hypoparathyroidism. Clin Endocrinol 2012;77:200-6.

17. Modi S, Tripathi M, Saha S, Goswami R. Seizures in patients with idiopathic hypoparathyroidism: effect of antiepileptic drug withdrawal on recurrence of seizures and serum calcium control. Eur J Endocrinol 2014;170: 777-83. 